\section{Hyponatremia: terminology and more}

$\mathrm{K}$ aren Yeates and associates ${ }^{1}$ are to be commended for their concise, pragmatic and expert update on hyponatremia. However, they implicitly endorse a previously described concept - low effective circulating volume ${ }^{2}$ which is offered to account for why sodium retention in heart failure persists despite established volume overload. In fact, this concept is physiologically unsound.

First, the circulating volume comprises plasma volume plus interstitial volume, the 2 major components of extracellular volume (also known as sodium space). Since this volume is not further partitioned either anatomically or physiologically, it is "effective" in its entirety and is expanded in heart failure. Thus, the qualifier "effective" is inapplicable overall, and the adjectives "low" and "contracted" are inapplicable in the context of heart failure.

Second, although it has been fashionable to dismiss the role of low cardiac output in heart failure, it is in fact the central pathophysiologic element "not only of advanced heart failure (systolic and/or diastolic) but also of the earliest stages of the underlying ventricular dysfunction, long before heart failure is symptomatic or detectable at the bedside." ${ }^{\prime}$ Indeed, low cardiac output is the driving force for virtually the entire heart failure syndrome, including persistent sodium retention despite established hypervolemia, ${ }^{3}$ neurohormonal hyperactivation (in a futile attempt to preserve cardiac output, but at the expense of further cardiac and vascular dysfunction $)^{3}$ and elevation of natriuretic peptides and troponins. Neglect of this reality has fostered the conceptual aberration "low effective circulating volume ${ }^{{ }_{3,4}}$ and the proliferation of various models of heart failure (each further obscuring the central role of low cardiac output ${ }^{3}$ ) and has delayed elucidation of the true pathophysiology of diastolic heart failure and several other issues related to heart failure in general., ${ }^{3,4}$

This might be mere pedantry were it not for the risk that use of the term "low effective circulating volume" poses to patients. Advanced congestive heart failure typically presents with high venous pressure - jugular or pulmonary or both - and frequently with high renal function indices (blood urea nitrogen and creatinine). High renal function indices in this setting, in the absence of another explanation, are too often perceived as a sign of hypovolemia, despite clearly elevated venous pressure. The natural therapeutic response, which in fact is potentially countertherapeutic if not hazardous, would be to attenuate any pre-existing regimen or to supplement circulatory volume.

In cases of advanced heart failure, the cardiac output (Starling) curve commonly exhibits a "descending limb" effect, whereby therapeutic lowering of venous pressure actually increases cardiac output. ${ }^{5-7}$ Thus, aggressive diuretic therapy not only alleviates the congestive phenomena as expected, but also (by increasing cardiac output and hence renal perfusion), typically and dramatically lowers the renal function indices. Indeed, the notion that excessive venous pressure must be maintained to preserve cardiac output in heart failure has long been dispelled; it is only when venous pressure falls below a value approximately $50 \%$ greater than the upper limit of the nor- 
mal range that cardiac output begins to further decline.?

I would respectfully suggest that the term "low effective circulating volume" be expunged from the heart failure lexicon. Not only is it physiologically unsound, but it also invites the misperception that high renal function indices in advanced congestive heart failure are a sign of extracellular volume contraction.

\section{Philip Andrew \\ Watertown, NY}

\section{References}

1. Yeates KE, Singer M, Morton AR. Salt and water: a simple approach to hyponatremia. CMA7 2004 170(3):365-9.

2. Schrier RW, Abraham WT. Hormones and hemodynamics in heart failure. N Engl 7 Med 1999; 341(8):577-85.

3. Andrew P. Diastolic heart failure demystified. Chest 2003;124(2):744-53.

4. Andrew P. Renin-angiotensin-aldosterone activation in heart failure, aldosterone escape [letter]. Chest 2002;122(2):755.

5. Bogaty P, Mure P, Dumesnil JG. New insights into diastolic dysfunction as the cause of acute left-sided heart failure associated with systemic hypertension and/or coronary artery disease. $A m$ 7 Cardiol 2002;89(3):341-5.

6. Atherton JJ, Moore TD, Lele SS, Thomson HL Galbraith AJ, Belenkie I, et al. Diastolic ventricular interaction in chronic heart failure. Lancet 1997;349(9067):1720-4.

7. Stevenson LW, Tillisch JH. Maintenance of cardiac output with normal filling pressures in patients with dilated heart failure. Circulation 1986; 74(6):1303-8.

Competing interests: None declared.

DOI:10.1503/cmaj.1040333

$\mathrm{K}$ aren Yeates and associates, ${ }^{1}$ in their article on the management of hyponatremia, use the terms "serum osmolality" and "tonicity" interchangeably, a common practice. Although there is not a major difference in meaning, it is important to differentiate these terms in this context. Tonicity is effective serum osmolality and is equal to serum osmolality minus the concentration of ineffective osmoles (mainly urea), since urea can diffuse in and out of the cell and is not an effective osmole.

In the algorithm for the management of hyponatremia (Fig. 1 of the paper), Yeates and associates ${ }^{1}$ advise assessing extracellular fluid (ECF) volume status after initial treatment of symptomatic acute or chronic hyponatremia, but this should be done before treatment is started. In cases of acute hyponatremia, treatment would not have any ill effects, but if the hyponatremia is chronic and is treated aggressively, the consequences could be fatal, especially in women. ${ }^{2}$ In addition, aggressive treatment of chronic hyponatremia secondary to syndrome of inappropriate secretion of antidiuretic hormone (SIADH) might lead to a worsening of the hyponatremia, ${ }^{3}$ as alluded to by Yeates and associates in the text of their article. ${ }^{1}$ If urine electrolyte levels are determined after treatment (i.e., after volume repletion), the results are often equivocal and thus may not be helpful in patient management.

In the section "The case revisited," the authors recommend an alternative medication to treat the patient's systolic hypertension. However, the patient is described as having taken a thiazide diuretic for 5 years with no previous history of hyponatremia. The acute episode of hyponatremia had a clear cause: volume depletion secondary to gastroenteritis and volume replacement with free water. It would be more appropriate to withhold the diuretic until the acute illness had resolved and to reintroduce it with caution, rather than changing the drug entirely.

\section{Malvinder S. Parmar}

Medical Director

Medical Program (Internal Medicine)

Timmins and District Hospital

Timmins, Ont.

\section{References}

1. Yeates KE, Singer M, Morton AR. Salt and water: a simple approach to hyponatremia. CMA7 2004; 170(3):365-9.

2. Arieff AI. Hyponatremia, convulsions, respiratory arrest, and permanent brain damage after elective surgery in healthy women. $N$ Engl $7 \mathrm{Med}$ 1986;314(24):1529-35.

3. Laureno R, Karp BI. Myelinolysis after correction of hyponatremia. Ann Intern Med 1997;126 (1):57-62.

Competing interests: None declared.

DOI:10.1503/cmaj.1050289

A s discussed by Karen Yeates and associates $^{1}$ in their review of hyponatremia, evaluation of extracellular volume is sometimes difficult. In a patient with hyponatremia, a trial of saline infusion may be useful in clarifying the diagnosis; however, contrary to information in the review, most patients with SIADH will not experience worsening of hyponatremia after infusion of isotonic saline. We found that only $30 \%$ of 33 consecutive patients with SIADH had a decrease in plasma sodium levels after infusion of $2 \mathrm{~L}$ of isotonic saline over 24 hours; ${ }^{2}$ our observations were similar for patients with urine osmolality above $530 \mathrm{mOsm} / \mathrm{L}$. $^{3}$

Yeates and associates" state that "hyponatremia should be corrected at a rate similar to that at which it developed," but this recommendation could be misleading. In the classical model used to induce osmotic demyelination syndrome in hyponatremic rats, initial serum sodium level was $142 \mathrm{mmol} / \mathrm{L}$ and decreased to $115 \mathrm{mmol} / \mathrm{L}$ after 24 hours, $113 \mathrm{mmol} / \mathrm{L}$ after 48 hours and $110 \mathrm{mmol} / \mathrm{L}$ after 72 hours. ${ }^{4}$ If the sodium level were to be corrected on the first day by $3 \mathrm{mmol} / \mathrm{L}$, on the second day by $2 \mathrm{mmol} / \mathrm{L}$ and on the third day by $27 \mathrm{mmol} / \mathrm{L}$, severe brain damage would develop, despite a correction rate similar to the rate of induction of hyponatremia. For the long-term management of SIADH in cases where water restriction is ineffective, we use demeclocycline, urea or furosemide, although immediate introduction of oral vasopressin V2 receptor antagonists may make management easier.,

\section{Guy Decaux}

Wim Musch

Alain Soupart

Erasmus University Hospital

Brussels, Belgium

\section{References}

1. Yeates KE, Singer M, Morton AR. Salt and water: a simple approach to hyponatremia. CMA7 2004; 170(3):365-9.

2. Musch W, Decaux G. Utility and limitations of biochemical parameters in the evaluation of hyponatremia in the elderly. Int Urol Nephrol 2001;32 (3):475-93.

3. Musch W, Decaux G. Treating the syndrome of inappropriate $\mathrm{ADH}$ secretion with isotonic saline. Q7M 1998;91(11):749-53.

4. Decaux G, Soupart A. Treatment of symptomatic hyponatremia. Am 7 Med Sci 2003;326(1): 25-30.

5. Decaux G. Long-term treatment of patients with inappropriate secretion of antidiuretic hormone by the vasopressin receptor antagonist conivaptan, urea, or furosemide. Am 7 Med 2001;110(7):582-4.

6. Decaux G, Musch W, Soupart A. Hyponatremia 